\title{
PENURUNAN MODEL BLACK SCHOLES DENGAN PERSAMAAN DIFERENSIAL STOKASTIK UNTUK OPSI TIPE EROPA
}

\author{
DESI SUSANTI, DODI DEVIANTO \\ Program Studi Matematika, \\ Fakultas Matematika dan Ilmu Pengetahuan Alam, Universitas Andalas, \\ Kampus UNAND Limau Manis Padang, Indonesia, \\ dhe_essusanti@yahoo.co.id,ddevianto@fmipa.unand.ac.id
}

\begin{abstract}
Abstrak. Opsi tipe Eropa adalah kontrak yang memberikan hak kepada pemilik atau pemegangnya untuk membeli atau menjual sejumlah aset (saham) suatu perusahaan tertentu dengan harga tertentu (harga pelaksanaan), yang dilaksanakan saat jatuh tempo saja. Harga opsi saham dapat ditentukan dengan model Black Scholes yang dirumuskan oleh Fisher Black dan Mayor Scholes pada tahun 1973. Model ini mengasumsikan bahwa harga saham tidak membayarkan dividen, tidak ada pembayaran pajak, suku bunga bebas resiko, dan opsi yang digunakan bertipe Eropa. Perubahan harga saham yang terjadi di pasar bergerak secara acak menurut waktu. Perubahan tersebut dapat diasumsikan mengikuti proses Wiener yang merupakan suatu gerak Brown. Perubahan harga saham yang mengikuti gerak Brown dapat diformulasikan kedalam suatu persamaan diferensial stokastik, dimana solusinya dapat menentukan model Black Scholes. Perhitungan harga opsi saham Sony Corporation periode 31 Desember 2012 sampai 31 Desember 2013 deng-an Black Scholes menunjukkan bahwa pada semua harga pelaksanaan yang dipakai sebaiknya opsi call dibeli karena harga opsi di pasar lebih rendah dibandingkan yang dihitung dengan Black Scholes, sedangkan untuk opsi put pada harga pelaksanaan 19.00 dolar sebaiknya opsi dijual.
\end{abstract}

Kata Kunci: Opsi, proses stokastik, persamaan diferensial stokastik, model Black Scholes

\section{Pendahuluan}

Dalam perkembangan ilmu matematika, banyak penerapannya yang dapat diaplikasikan ke bidang lain. Salah satu aplikasi ilmu matematika adalah dalam masalah investasi. Dalam investasi, seorang investor memiliki pilihan untuk membeli aset yang diperdagangkan secara langsung di pasar keuangan atau membeli aset derivatif. Aset derivatif merupakan suatu instrumen keuangan yang nilainya bergantung kepada aset yang mendasarinya. Salah satu produk derivatif yang banyak dikenal adalah opsi.

Opsi adalah suatu jenis kontrak antara dua pihak, yang mana satu pihak memberikan hak kepada pihak lain untuk menjual atau membeli aset tertentu pada harga dan periode tertentu [5]. Berdasarkan jenis hak yang diberikan, opsi dapat dibedakan menjadi dua yaitu opsi call dan opsi put. Opsi call adalah suatu tipe kontrak yang memberikan hak kepada pemegang opsi untuk membeli dari penjual opsi sejumlah lembar saham tertentu pada harga dan jangka waktu tertentu. Opsi put merupakan opsi yang memberikan hak kepada pemegangnya untuk menjual saham 
dalam jumlah tertentu kepada pembeli opsi pada waktu dan harga yang telah ditentukan. Sedangkan berdasarkan periode waktu penggunaan, opsi dapat dibedakan menjadi dua yaitu opsi tipe Eropa dan opsi tipe Amerika [3]. Tipe Eropa menunjukkan bahwa opsi tersebut dapat dilaksanakan pada saat jatuh tempo saja. Sedangkan tipe Amerika menunjukkan bahwa opsi tersebut dapat dilaksanakan pada saat jatuh tempo atau sebelumnya. Fisher Black dan Mayor Scholes pada tahun 1973 merumuskan suatu metode untuk menetapkan harga opsi. Metode tersebut dikenal dengan model Black Scholes. Model Black Scholes hanya dapat digunakan pada saat jatuh tempo saja, sehingga dalam penulisan ini yang akan dibahas adalah untuk opsi tipe Eropa, karena opsi tipe Eropa dilaksanakan pada saat jatuh tempo saja.

Perubahan harga saham yang terjadi di pasar bergerak secara acak menurut waktu. Perubahan tersebut dapat diasumsikan mengikuti proses Wiener yang merupakan suatu gerak Brown, sehingga dapat dinyatakan juga bahwa harga saham mengikuti gerak Brown yang bergantung kepada waktu. Perubahan harga saham yang mengikuti gerak Brown tersebut dapat diformulasikan kedalam suatu persamaan diferensial stokastik, dimana solusinya dapat menentukan model Black Scholes. Oleh karena itu, dalam paper ini akan dilakukan penurunan model Black Scholes menggunakan persamaan diferensial stokastik dan penentuan opsi call dan opsi put tipe Eropa dengan menggunakan data harga penutupan saham Sony Corporation selama satu tahun.

\section{Pemodelan Harga Saham dengan Gerak Brown}

Bila harga saham pada waktu $t$ yang dinotasikan dengan $S(t)$ dimodelkan dengan gerak Brown, maka perubahan harga saham tersebut dapat ditulis sebagai berikut.

$$
d S(t)=\mu S(t) d t+\sigma S(t) d W(t),
$$

dengan $\mu S(t) d t$ adalah komponen deterministik, $\sigma S(t) d W(t)$ adalah komponen stokastik, dan $W(t)$ adalah proses Wiener. Sedangkan $\mu$ dan $\sigma$ masing-masing menya-takan mean dan volatilitas dari harga saham tersebut.

Berdasarkan [1], apabila harga saham $S(t)$ mengikuti model saham pada persamaan $d S(t)=\mu S(t) d t+\sigma S(t) d W(t)$, maka bentuk persamaan diferensial stokastik untuk $X(t)=f(S(t), t)$ dengan $t \in[0, \infty)$ dapat dinyatakan dalam bentuk

$$
d X(t)=\left(\mu S(t) \frac{\partial f}{\partial s}+\frac{\partial f}{\partial t}+\frac{1}{2} \sigma^{2} S(t)^{2} \frac{\partial^{2} f}{\partial s^{2}}\right) d t+\sigma S(t) \frac{\partial f}{\partial s} d W(t)
$$

\section{Penentuan Harga Opsi dengan Persamaan Diferensial Stokastik}

Dalam melakukan investasi, misalkan seorang investor memiliki kekayaan awal sebesar $X(0)$, dan tiap saat $t$ ia memiliki investasi dalam bentuk kepemilikan saham sebanyak $\Delta(t)$ lembar, dengan harga tiap lembar sebesar $S(t)$. Bila $X(0)<\Delta(t) S(t)$ maka investor akan meminjam, dan sebaliknya investor akan menyimpan uang bila $X(0)>\Delta(t) S(t)$ dengan bunga sebesar $r$ per tahun. Misalkan $X(t)$ menyatakan kekayaan investor pada saat $t$, maka proses kekayaan dari investor tersebut da- 
pat dinyatakan sebagai penjumlahan dari pertumbuhan nilai saham dan pertumbuhan tabungan, atau penjumlahan dari penyusutan nilai saham dan pertumbuhan hutang, yaitu

$$
\begin{aligned}
d X(t) & =\Delta(t) d S(t)+r[X(t)-\Delta(t) S(t)] d t, \\
& =\Delta(t)[\mu S(t) d t+\sigma S(t) d W(t)]+r[X(t)-\Delta(t) S(t)] d t, \\
& =[r X(t)+\Delta(t) S(t)(\mu-r)] d t+\Delta(t) \sigma S(t) d W(t) .
\end{aligned}
$$

Selanjutnya, berdasarkan [4], dapat pula ditentukan nilai opsi call dan opsi put yang dapat dijelaskan sebagai berikut. Misalkan $V(S(t), t)$ adalah nilai opsi call pada saat $t$, dengan harga saham sebesar $S(t)$. Apabila hal ini dinyatakan dalam bentuk diferensial maka dapat ditulis sebagai berikut.

$d V(S(t), t)=\frac{\partial V}{\partial t} d t+\frac{\partial V}{\partial S(t)} \mu S(t) d t+\frac{\partial V}{\partial S(t)} \sigma S(t) d W(t)+\frac{1}{2} \frac{\partial^{2} V}{\partial(S(t))^{2}} \sigma^{2}(S(t))^{2} d t$.

Setiap saat $t$, nilai kekayaan $X(t)$ harus dapat menutup $V(S(t), t)$. Untuk memastikan bahwa $X(t)=V(S(t), t)$ untuk setiap $t$, koefisien pada masing-masing diferensialnya disamakan dan dapat dituliskan kembali menjadi persamaan diferensial stokastik model Black Scholes sebagai berikut.

$$
\begin{aligned}
\frac{\partial V}{\partial t}+\frac{\partial V}{\partial S(t)} \mu S(t)+\frac{1}{2} \frac{\partial^{2} V}{\partial(S(t))^{2}} \sigma^{2}(S(t))^{2} & =r V+S(t)(\mu-r) \frac{\partial V}{\partial S(t)}, \\
\frac{\partial V}{\partial t}+r S \frac{\partial V}{\partial S}+\frac{1}{2} \sigma^{2} S^{2} \frac{\partial^{2} V}{\partial S^{2}} & =r V,
\end{aligned}
$$

yang memenuhi kondisi awal untuk opsi call dan opsi put dengan harga pelaksanaan $K$ dan waktu pelaksanaan $T$ sebagai berikut:

$$
V(S(t), t)=\max \{S(t)-K, 0\}, \quad P(S(t), t)=\max \{K-S(t), 0\} .
$$

\section{Penurunan Model Black Scholes untuk Opsi Call dan Opsi Put pada Opsi Tipe Eropa}

Penurunan model Black Scholes untuk opsi call dan opsi put pada opsi tipe Eropa dilakukan dengan menggunakan persamaan differensial stokastik yang merujuk pada [4] dan [6]. Misalkan transformasi tahap pertama yaitu:

$$
\begin{aligned}
S(t) & =K e^{x}, \\
t & =T-\frac{2 \tau}{\sigma^{2}}, \\
V(S(t), t) & =K C(x, \tau) .
\end{aligned}
$$

Dari transformasi di atas diperoleh

$$
\begin{aligned}
\frac{\partial V}{\partial t} & =-\frac{1}{2} \sigma^{2} K \frac{\partial(C(x, \tau))}{\partial \tau} \\
\frac{\partial V}{\partial(S(t))} & =e^{-x} \frac{\partial(C(x, \tau))}{\partial x} \\
\frac{\partial^{2} V}{\partial(S(t))^{2}} & =\left(e^{-x} \frac{\partial(C(x, \tau))}{\partial x}+e^{-x} \frac{\partial^{2}(C(x, \tau))}{\partial x^{2}}\right) \frac{e^{-x}}{K} .
\end{aligned}
$$


20 Desi Susanti, Dodi Devianto

Dengan mensubstitusikan (4.4) - (4.6) ke (3.1), diperoleh

$$
\frac{\partial(C(x, \tau))}{\partial \tau}=\frac{\partial^{2}(C(x, \tau))}{\partial x^{2}}+(k-1) \frac{\partial(C(x, \tau))}{\partial x}-k C(x, \tau),
$$

dengan

$$
k=\frac{r}{\frac{1}{2} \sigma^{2}} .
$$

Dengan mensubstitusikan (4.1) ke (3.2) diperoleh

$$
V(S(t), t)=K \max \left\{e^{x}-1,0\right\} .
$$

Persamaan (4.9) menjadi kondisi awal untuk (4.7) dengan mempertimbangkan bahwa hubungan berikut bisa diperoleh dari (4.3), yaitu

$$
V(S(t), t)=K C(x, 0) .
$$

Dari (4.9) dan (4.10) diperoleh kondisi awal untuk (4.7) yaitu:

$$
C(x, 0)=\max \left\{e^{x}-1,0\right\} .
$$

Misalkan

$$
C(x, \tau)=e^{\alpha x+\beta \tau} u(x, \tau) .
$$

Maka

$$
\begin{aligned}
\frac{\partial C(x, \tau)}{\partial \tau} & =e^{\alpha x+\beta \tau}\left(\beta u+\frac{\partial u}{\partial \tau}\right), \\
\frac{\partial C(x, \tau)}{\partial x} & =e^{\alpha x+\beta \tau}\left(\alpha u+\frac{\partial u}{\partial x}\right), \\
\frac{\partial^{2} C(x, \tau)}{\partial x^{2}} & =e^{\alpha x+\beta \tau}\left(\alpha^{2} u+2 \alpha \frac{\partial u}{\partial x}+\frac{\partial^{2} u}{\partial x^{2}}\right) .
\end{aligned}
$$

Selanjutnya, substitusikan (4.12) - (4.14) ke (4.7), sehingga diperoleh

$$
\alpha=-\frac{1}{2}(k-1), \quad \beta=-\frac{1}{4}(k+1)^{2} .
$$

Akibatnya (4.11) menjadi

$$
C(x, \tau)=e^{-\frac{1}{2}(k-1) x-\frac{1}{4}(k+1)^{2} \tau} u(x, \tau) .
$$

Dari (4.15) diperoleh nilai $\frac{\partial C}{\partial x}, \frac{\partial C}{\partial \tau}$, dan $\frac{\partial^{2} C}{\partial x^{2}}$. Hasil-hasil tersebut disubstitusikan ke (4.7), sehingga diperoleh persamaan difusi sebagai berikut.

$$
\frac{\partial u(x, \tau)}{\partial \tau}=\frac{\partial^{2} u(x, \tau)}{\partial x^{2}}
$$

dengan kondisi awal

$$
C(x, 0)=e^{-\frac{1}{2}(k-1) x} u(x, 0),
$$

atau dapat ditulis juga

$$
\begin{aligned}
u(x, 0) & =e^{\frac{1}{2}(k-1) x} C(x, 0) \\
& =\max \left(e^{\frac{1}{2}(k+1) x}-e^{\frac{1}{2}(k-1) x}, 0\right) .
\end{aligned}
$$


Pada langkah selanjutnya akan dicari solusi $u(x, \tau)$ untuk opsi call yang memenuhi persamaan difusi (4.16) dengan kondisi awal

$$
u(x, 0)=f(x) .
$$

Pertama-tama, misalkan bahwa

$$
u(x, \tau)=F(x) G(\tau),
$$

sehingga diperoleh

$$
\frac{\partial u}{\partial \tau}=F \frac{d G}{d \tau}, \quad \frac{\partial u}{\partial x}=G \frac{d F}{d x}, \quad \frac{\partial^{2} u}{\partial x^{2}}=G \frac{d^{2} F}{d x^{2}} .
$$

Maka persamaan difusi (4.16) dapat ditulis kembali sebagai berikut.

$$
\frac{1}{G} \frac{d G}{d \tau}=\frac{1}{F} \frac{d^{2} F}{d x^{2}} .
$$

Dari (4.18) dapat dilihat bahwa perubahan nilai $\tau$ hanya akan merubah persamaan yang ada di ruas kiri dan perubahan nilai $x$ hanya akan merubah persamaan yang ada di sebelah kanan. Sehingga (4.18) ditulis kembali sebagai berikut.

$$
\frac{1}{G} \frac{d G}{d \tau}=\frac{1}{F} \frac{d^{2} F}{d x^{2}}=k
$$

Adapun konstanta $k$ haruslah negatif yaitu $k=-p^{2}$ agar nilai $(u(x, \tau))$ konvergen ke 0 untuk $\tau \rightarrow \infty$. Sehingga diperoleh solusi dari (4.19) sebagai berikut.

$$
\begin{aligned}
G & =e^{k \tau}, \\
F(x) & =A \cos (p x)+B \sin (p x) .
\end{aligned}
$$

Dari (4.20) - (4.21) didapatkan nilai $u(x, \tau, p)$ sebagai berikut, dengan memilih $A(p)$ dan $B(p)$ yang merupakan suatu fungsi dari $p$,

$$
u(x, \tau ; p)=(A \cos (p x)+B \sin (p x)) e^{-p^{2} \tau} .
$$

Karena persamaan difusi tersebut linier dan homogen, maka

$$
u(x, \tau)=\int_{0}^{\infty}(A(p) \cos (p x)+B(p) \sin (p x)) e^{-p^{2} \tau} d p,
$$

dengan

$$
f(x)=u(x, 0)=\int_{0}^{\infty}(A(p) \cos (p x)+B(p) \sin (p x)) d p,
$$

yang merupakan suatu bentuk integral Fourier sehingga nilai $A(p)$ dan $B(p)$ dapat dinyatakan sebagai

$$
\begin{aligned}
& A(p)=\frac{1}{\pi} \int_{-\infty}^{\infty} f(v) \cos (p v) d v \\
& B(p)=\frac{1}{\pi} \int_{-\infty}^{\infty} f(v) \sin (p v) d v
\end{aligned}
$$

Dengan mensubstitusikan (4.23) - (4.24) ke (4.22) diperoleh

$$
u(x, \tau)=\frac{1}{\pi} \int_{-\infty}^{\infty} f(v) \int_{0}^{\infty}(\cos (p(v-x))) e^{-p^{2} \tau} d p d v .
$$


Perhatikan bahwa

$$
\int_{0}^{\infty}(\cos (2 a u)) e^{-u^{2}} d u=\frac{\sqrt{\pi}}{2} e^{-a^{2}}
$$

Selanjutnya, misalkan

$$
\begin{aligned}
p^{2} \tau=u^{2} \text { atau } u= \pm p \sqrt{\tau} \Leftrightarrow d u= \pm d p \sqrt{\tau} \Leftrightarrow d p= \pm \frac{1}{\sqrt{\tau}} d u, \\
2 a u=p(v-x) \text { atau } a=\frac{v-x}{2} \frac{p}{u}=\frac{v-x}{2 \sqrt{\tau}} .
\end{aligned}
$$

Akibatnya diperoleh

$$
\int_{0}^{\infty}(\cos (p(v-x))) e^{-p^{2} \tau} d p=\frac{\sqrt{\pi}}{(2 \sqrt{\tau})} e^{-\frac{(x-v)^{2}}{4 \tau}} .
$$

Dengan demikian (4.25) dapat ditulis menjadi

$$
u(x, \tau)=\frac{1}{2 \sqrt{\pi \tau}} \int_{-\infty}^{\infty} f(v) e^{-\frac{(x-v)^{2}}{4 \tau}} d v
$$

dengan

$$
f(v)=\max \left\{e^{\frac{1}{2}(k+1) v}-e^{\frac{1}{2}(k-1) v}, 0\right\}
$$

Selanjutnya akan dicari solusi $u(x, \tau)$ dengan mensubstitusikan nilai $f(v)$ ke $(4.27)$, sehingga diperoleh

$$
\begin{aligned}
u(x, \tau) & =\frac{1}{2 \sqrt{\pi \tau}} \int_{0}^{\infty} e^{\left[\frac{1}{2}(k+1) v-\frac{1}{4 \tau}(x-v)^{2}\right]} d v-\frac{1}{2 \sqrt{\pi \tau}} \int_{0}^{\infty} e^{\left[\frac{1}{2}(k-1) v-\frac{1}{4 \tau}(x-v)^{2}\right]} d v \\
& =I_{1}-I_{2}
\end{aligned}
$$

Dengan melakukan penyederhanaan pada masing-masing integran dari $I_{1}$ dan $I_{2}$ yaitu:

$$
\begin{aligned}
& \frac{1}{2}(k+1) v-\frac{1}{4 \tau}(x-v)^{2}=-\frac{1}{2}\left[\frac{v-(x+\tau(k+1))}{\sqrt{2 \tau}}\right]^{2}+\frac{2 x(k+1)+\tau(k+1)^{2}}{4} \\
& \frac{1}{2}(k-1) v-\frac{1}{4 \tau}(x-v)^{2}=-\frac{1}{2}\left[\frac{v-(x+\tau(k-1))}{\sqrt{2 \tau}}\right]^{2}+\frac{2 x(k-1)+\tau(k-1)^{2}}{4} .
\end{aligned}
$$

Akibatnya $I_{1}$ dapat dinyatakan sebagai berikut.

$$
I_{1}=\frac{1}{2 \sqrt{\pi \tau}} e^{\frac{2 x(k+1)+\tau(k+1)^{2}}{4}} \int_{0}^{\infty} e^{-\frac{1}{2}\left[\frac{v-(x+\tau(k+1))}{\sqrt{2 \tau}}\right]^{2}} d v .
$$

Selanjutnya, misalkan

$$
z=\frac{v-(x+\tau(k+1))}{\sqrt{2 \tau}} \Leftrightarrow d z=\frac{1}{\sqrt{2 \tau}} d v \leftrightarrow d v=\sqrt{2 \tau} d z,
$$


sehingga diperoleh

$$
\begin{aligned}
I_{1} & =\frac{1}{\sqrt{2 \pi}} e^{\frac{2 x(k+1)+\tau(k+1)^{2}}{4}} \int_{-\frac{x+\tau(k+1)}{\sqrt{2 \tau}}}^{\infty} e^{-\frac{1}{2} z^{2}} d z \\
& =e^{\frac{2 x(k+1)+\tau(k+1)^{2}}{4}} \frac{1}{\sqrt{2 \pi}} \int_{a}^{\infty} e^{-\frac{1}{2} z^{2}} d z \\
& =e^{\frac{2 x(k+1)+\tau(k+1)^{2}}{4}} N(-a) \\
& =e^{\frac{2 x(k+1)+\tau(k+1)^{2}}{4}} N\left(d_{1}\right) .
\end{aligned}
$$

Dengan cara yang sama diperoleh $I_{2}$ sebagai berikut

$$
I_{2}=e^{\frac{2 x(k-1)+\tau(k-1)^{2}}{4}} N\left(d_{2}\right), \quad d_{2}=\frac{(x+\tau(k-1))}{\sqrt{2 \tau}} .
$$

Dari (4.29) - (4.30) diperoleh nilai $I_{1}$ dan $I_{2}$, yang disubstitusikan ke (4.28) untuk memperoleh

$$
u(x, \tau)=e^{\frac{2 x(k+1)+\tau(k+1)^{2}}{4}} N\left(d_{1}\right)-e^{\frac{2 x(k-1)+\tau(k-1)^{2}}{4}} N\left(d_{2}\right) .
$$

Substitusikan (4.31) ke (4.15) sehingga diperoleh

$$
C(x, \tau)=e^{x} N\left(d_{1}\right)-e^{-k \tau} N\left(d_{2}\right) .
$$

Dengan asumsi pada (4.1) - (4.3), dan (4.8), diperoleh formula Black Scholes untuk opsi call tipe Eropa sebagai berikut.

$$
V(S(t), T)=S(t) N\left(d_{1}\right)-K e^{-r(T-t)} N\left(d_{2}\right) .
$$

Selanjutnya dengan menggunakan prinsip put call parity, yaitu $S+P-V=$ $K e^{-r(T-t)}$, diperoleh model Black Scholes untuk opsi put sebagai berikut

$$
P(S(t), T)=K e^{-(T-t)} N\left(-d_{2}\right)-S(t) N\left(-d_{1}\right),
$$

dengan

$$
\begin{aligned}
& d_{1}=\frac{\ln \left(\frac{S_{t}}{K}\right)+\left(r+\frac{1}{2} \sigma^{2}\right)(T-t)}{\sigma \sqrt{(T-t)}}, \\
& d_{2}=\frac{\ln \left(\frac{S_{t}}{K}\right)+\left(r-\frac{1}{2} \sigma^{2}\right)(T-t)}{\sigma \sqrt{(T-t)}} .
\end{aligned}
$$

\section{Studi Kasus Model Black Scholes pada Saham Sony Corporation}

Untuk studi kasus pada model Black Scholes ini, digunakan data saham Sony Corporation pada tanggal 31 Desember 2012 sampai 31 Desember 2013 yang diakses langsung dari http://www.yahoofinance.com.

Faktor yang mempengaruhi dalam perhitungan model Black Scholes yaitu, yang pertama nilai volatilitas yang dihitung dengan mencari simpangan baku dari logaritma natural return saham yaitu

$$
\sigma=\sqrt{n \hat{R}}=\sqrt{253 * 0.000577}=0.3821
$$


dengan

$$
\begin{aligned}
\hat{R} & =\frac{\sum_{t-1}^{n}\left(\hat{R}_{t}-R\right)^{2}}{n-1}, \\
R & =\frac{\sum_{t-1}^{n} \hat{R}_{t}}{n} \\
\hat{R}_{t} & =\ln \frac{S_{t+1}}{S_{t}}, t=1,2, \cdots, n-1 .
\end{aligned}
$$

Tingkat suku bunga bebas resiko $(r)$ : 0.0025, yang diakses langsung melalui http://www.fixstreet.com/fundamental/interest-rate-table/, harga saham awal tanggal 31 Desember $2013\left(S_{0}\right)$ : 17.29 dolar, waktu jatuh tempo dipilih pada 18 Januari 2013, yang berarti perioda waktu pembayaran opsi adalah 18 hari. Maka nilai $(T-t)=\frac{18}{365}=0.049315$, harga pelaksanaan $(K): 17.00,17.5018 .00,19.00,19.50$.

Pertama, untuk harga pelaksanaan 17.00 dolar diperoleh nilai $d_{1}=0.24322$, dan $d_{2}=0.15837$. Selanjutnya dapat dicari nilai $N\left(d_{1}\right), N\left(d_{2}\right), N\left(-d_{1}\right)$ dan $N\left(-d_{2}\right)$, dengan menggunakan perintah NORMSDIST yang ada pada software Microsoft Excel. Kemudian dengan menggunakan model Black Scholes dihitung harga opsi call yang hasilnya $V=0.7378$, dan harga opsi put yang hasilnya $P=0.44578$. Selanjutnya dengan cara yang sama diperoleh harga opsi call dan opsi put untuk harga pelaksanaan yang berbeda yaitu:

Tabel 1. Harga pelaksanaan dan harga opsi call dan opsi put pada model Black Scholes

\begin{tabular}{|c|c|c|c|c|c|}
\hline No & $\begin{array}{c}\text { Harga Saham } \\
\text { Awal }\end{array}$ & $\begin{array}{c}\text { Harga } \\
\text { Pelaksanaan }\end{array}$ & Waktu & Opsi Call & Opsi Put \\
\hline 1 & 17.29 & 17.00 & 0.049315 & 0.7378 & 0.44578 \\
\hline 2 & 17.29 & 17.50 & 0.049315 & 0.4905 & 0.69837 \\
\hline 3 & 17.29 & 18.00 & 0.049315 & 0.30867 & 1.01646 \\
\hline 4 & 17.29 & 19.00 & 0.049315 & 0.18369 & 1.3914 \\
\hline 5 & 17.29 & 19.50 & 0.049315 & 0.10339 & 1.81105 \\
\hline
\end{tabular}

Selanjutnya akan dibandingkan harga opsi yang dihitung menggunakan model Black Scholes dengan harga opsi di pasar saham dengan tujuan untuk mengetahui seberapa besar perbedaan harga opsi hitung menggunakan Black Scholes dengan opsi yang ditawarkan di pasar untuk dijadikan acuan oleh investor dalam melakukan investasi. Berikut adalah grafik perbandingannya.

Berdasarkan grafik di atas dapat dilihat bahwa harga opsi call yang dihitung dengan menggunakan model Black Scholes mendekati harga opsi yang ada di pasaran, dimana sumbu-X merupakan data harga pelaksanaan seperti yang ada pada tabel sebelumnya dan sumbu-Y merupakan harga opsi. Dari grafik dapat terlihat bahwa untuk opsi call semakin besar harga pelaksanaan maka nilai opsi call akan semakin rendah, sedangkan untuk opsi put semakin besar harga pelakasanaan maka nilai opsi put akan semakin tinggi. Hal ini menyatakan bahwa untuk opsi 

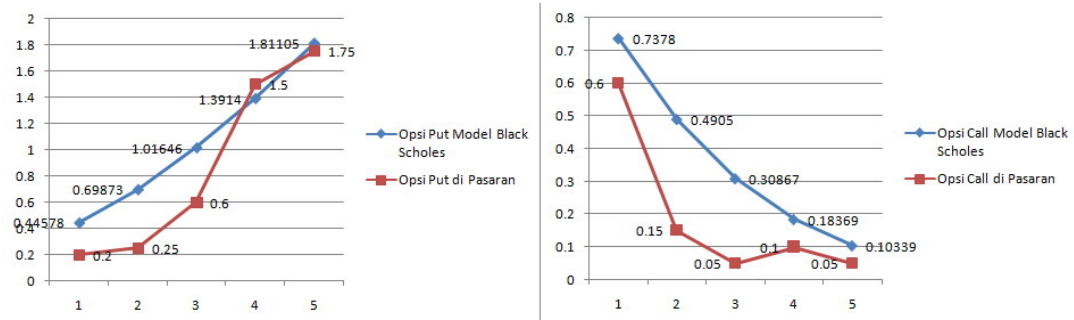

Gambar 1. Grafik perbandingan harga saham model Black Scholes dan harga saham di pasar

put semakin besar harga pelaksanaan maka semakin besar keuntungan yang akan diperoleh, dan sebaliknya untuk opsi call.

Berdasarkan grafik juga dapat dilihat bahwa untuk semua harga pelaksanaan opsi call sebaiknya opsi dibeli karena harga opsi call yang ada di pasaran lebih rendah dibandingkan dengan harga opsi call yang dihitung dengan model Black Scholes. Sedangkan untuk opsi put, pada harga pelaksanaan 19.00 dolar, harga opsi put yang ada di pasaran lebih tinggi dibandingkan dengan yang dihitung dengan model Black Scholes, oleh karena itu opsi sebaiknya dijual. Tetapi untuk harga pelaksanaan yang lain, sebaiknya opsi tidak dijual karena akan mengakibatkan kerugian.

Dari data yang dilihat pada tanggal 18 Januari 2014, harga saham Sony Corporation adalah 17.06 dolar, berarti harga saham mengalami penurunan. Oleh karena itu, pembeli opsi call yang memegang harga pelaksanaan di atas 17.06 dolar tidak memiliki kewajiban untuk membeli atau melaksanakan opsinya, karena akan lebih menguntungkan jika dia membeli saham Sony Corporation di pasar saham deng-an harga 17.06 dolar. Sebaliknya untuk opsi put, pembeli opsi put yang dalam kontrak opsi memegang harga pelaksanaan di atas 17.06 dolar akan mendapatkan keuntungan jika melaksanakan opsinya.

\section{Penutup}

Model Black Scholes untuk opsi call dan opsi put tipe Eropa yang diturunkan dengan persamaan diferensial stokastik adalah

$$
\begin{aligned}
& V(S(T), T)=S_{t} N\left(d_{1}\right)-K e^{-r(T-t)} N\left(d_{2}\right) \\
& P(S(T), T)=K e^{-r(T-t)} N\left(-d_{2}\right)-S_{t} N\left(-d_{1}\right),
\end{aligned}
$$

dengan $d_{1}=\frac{\ln \left(\frac{S_{t}}{K}\right)+\left(r+\frac{1}{2} \sigma^{2}\right)(T-t)}{\sigma \sqrt{(T-t)}}, \quad d_{2}=\frac{\ln \left(\frac{S_{t}}{K}\right)+\left(r-\frac{1}{2} \sigma^{2}\right)(T-t)}{\sigma \sqrt{(T-t)}}$.

Jika harga opsi call yang dihitung dengan model Black Scholes lebih tinggi dibandingkan dengan harga opsi call di pasar saham, maka investor sebaiknya membeli opsinya, karena harga yang dibeli lebih rendah dari taksiran yang telah dihitung, begitupun sebaliknya. Sedangkan untuk opsi put apabila harga opsi put di pasar saham lebih rendah dibandingkan dengan harga opsi put yang ditaksir dengan model Black Scholes maka sebaiknya investor tidak menjual opsinya, karena akan mengalami kerugian.

Untuk opsi call semakin tinggi harga pelaksanaan maka harga opsi akan semakin 
Desi Susanti, Dodi Devianto

kecil. Sebaliknya untuk opsi put semakin tinggi harga pelaksanaan maka harga opsi put akan semakin besar. Untuk opsi call apabila harga saham saat jatuh tempo mengalami penurunan maka pembeli opsi call berhak tidak melaksanakan opsinya, sedangkan untuk opsi put apabila saham mengalami penurunan saat jatuh tempo maka sebaiknya opsi dilaksanakan karena akan memperoleh keuntungan.

\section{Daftar Pustaka}

[1] Capinski, M and T. Zastawniak. 2004. Mathematics for Finance : An Introduction to Financial Engineering. Springer

[2] Closing price. 2013. Available at: http://www.finance.yahoo.com. [diakses pada 31 Desember 2013].

[3] Luenberger, D.G. 1998. Investment Science. Oxford University Press. New York.

[4] Oksendal B. 2003. Stochastic Differensial Equation (An Introduction with Application). $6^{\text {th }}$ ed. Germany. Springer Verlag.

[5] Ruey, S. T. 2000. Analysis of Financial Time Series. John Wiley and Sons. USA.

[6] Syamsuddin, M. Matematika Keuangan.http://personal.fmipa.itb.ac.id/ novriana/files/2011/09/Matematika-Keuangan1.pdf. Diakses pada 28 Oktober 2013. 